in five specific fields of science shortly to be submitted by scientists from Austria, Czechoslovakia, Hungary, Italy, Poland, Romania and Yugoslavia, in liaison with Unesco to the governments of the countries participating in the scheme, and to take note with particular interest of the fact that this scheme aims at defining ad hoc international agreements open to all interested European Member States.

\section{To Unesco :}

1 to help promote within the scientific community of the region, primarily through Unesco's European Bureau for scientific co-operation, the following principles :

(i) that in active scientific work the unofficial, international co-operation between scientists and scientific institutions has been and will continue to be an important form of communication;

(ii) that co-operation in science and movements of scientists should have their roots in the needs of scientific research itself and should also take account of national priorities ;

(iii) that, like science itself, the pattern of co-operation and exchange should continue to be pluralistic ;

(iv) that the academies, research councils and other research supporting organizations have an important role to play in fostering co-operation in European and world science.

2 to take, without prejudice to the above principles, all other measures as may be appropriate, to promote scientific contacts within such priority research fields as may from time to time be selected for European co-operation.

3 to conduct a survey of 'big science' taking into account the facilities which exist in Europe, and to give a view of existing capacity to accommodate foreign research teams or individual scientists.

4 to make a comparative analysis of the respective merits and demerits of the various existing vehicles, mechanisms and modalities of European scientific co-operation.

To the competent

International Organizations :

To support the guidelines set out in this recommendation, and to contribute, whenever appropriate and feasible, to their full implementation.

\section{United Nations Conference on the Human Environment}

After four years of preparation, the United Nations Conference on the Human Environment took place in Stockholm from 5-18 June 1972. Government delegations from more than 100 countries, representatives of international organisations, and several hundred observers met and discussed the problems of man and his environment. The European Physical Society was invited to attend this conference as a NonGovernmental Observer. D.J. Kroon from Eindhoven, the Netherlands, represented the EPS and he gives his opinion on this important meeting.

It is, of course, impossible to give a concise report on a meeting as the Stockholm conference. Several hundred talks, statements and reports were presented on a great variety of problems concerning the human environment. Air and water pollution, seas and oceans, social and economic problems, development strategy, food contamination, international trade, monitoring systems and many other subjects were treated in more, or less, detail. This report has, therefore, to be incomplete and reflects only a few aspects of the conference.

\section{Preparations}

In 1968 the Swedish government proposed that the United Nations should convene an international conference on the human environment 'because air pollution, water pollution, erosion, soil deterioration, unplanned urbanisation, traffic congestion, noise, etc., were rising at an alarming rate'.

The General Assembly of the United Nations accepted the proposal, established a preparatory committee, and appointed the Canadian Maurice F. Strong as Secretary General of the Conference. Consultations took place with more than 100 governments, with international organisations, with United Nations agencies and with many other groups. Several hundred reports were made and these resulted in six studies of 'subject areas' to be discussed during the conference :

1 Planning and management of human settlements for environmental quality.

2 Environmental aspects of natural resources management.

3 Identification and control of pollutants of broad international significance.

4 Educational, informational, social and cultural aspects of environmental issues.

5 Development and environment.

6 International organizational implications of action proposals.

These reports were the background of the 'Action plan for the human environment'. Each subject area report contained a long list of 'Recommendations for action', in which a great number of practical suggestions and measures were set out. Besides this action plan, a 'Declaration on the human environment', in which the principles of international behaviour and responsibilities were laid down, was one of the main topics of the conference.

\section{The Conference}

For the discussion of such a great number of problems of such different nature with so many delegations, two weeks was not enough. The Conference was therefore divided into four parallel sessions. Three committees discussed the reports mentioned above. Here, especially, the recommendations for action were considered and sometimes very carefully reformulated. These recommendations are to be the basis of laws in different countries, and hence precise agreements were necessary.

To give an example: One of the recommendations in subject area 3 was : 'It is recommended that Governments use the best practicable means to minimize the release to the environment of persistent and toxic substances, particulary heavy metals and organochlorine compounds...'. After quite a discussion this was changed to '... toxic or dangerous substances, especially if they are persistent, such as.... Although the result of this type of discussion is very important for future international action, the discussion itself is not very inspiring.

Besides these committee meetings, which were held every morning and afternoon (some even during the week-end) plenary sessions of the conference were convened twice each day. Here, the general policy, problems, backgrounds, measures and basic ideas were outlined as they existed in different countries. Also, international organizations which were involved with the environment in some 
way or another, could address the conference.

Even some 'alternative' groups could be heard in these sessions. At the same time, as the four sessions were meeting, an 'Environmental Forum' was running in Stockholm with papers and discussions by a great number of specialists in different fields.

The Stockholm conference was an experiment. An experiment in communication. It was clear that environmental problems of highly industrialized states are completely different from the problems of developing countries. For the latter, hunger, disease and low standard of living are the important factors which determine the environment that people have to live in; whereas high production, overconsumption, pollution, etc., determine the environmental problems of the industrialized countries. It was also clear that at such an international conference of a political nature, war and armament would be brought forward as environmental issues. It could hardly be denied that tests of nuclear weapons in the atmosphere, and defoliation, were as debatable as sources of air, water and soil contamination as the release of mercury in rivers, over-use of insecticides and ocean dumping. In spite of all the differences, the delegations never- theless noticed that most environmental problems may have aspects which have a common basis for which international co-operation would be necessary and possible in order to solve them. The 'action plan for the human environment' was, with a number of alterations, accepted. The governments agreed on a 'Declaration on the Human Environment'. That these agreements were possible proved that the communications-experiment was successful.

\section{After the Conference}

The decisions of the Stockholm Conference are to be confirmed by the next General Assembly of the United Nations and then the work can be started. From all the plans to be carried out, I only mention the installation of a world-wide measuring system. This will comprise 10 'baseline' stations in rural areas far from all sources of pollution to register longterm atmospheric and climatic changes. More than 100 stations of more regional scope will monitor the composition of the atmosphere. This system, which forms part of 'Earthwatch' has to provide data from which proliferation and sources of pollution can be studied.

Physicists and environmental problems Physics and physicists will be faced more and more with the necessity to contribute to the solutions of the world's major and crucial problems. Environmental research is badly needed. In the subject area studies, we find it stated many times that our knowledge on the environment is too fragmentary. Effective control measures are hampered by the gaps in our knowledge. On the other hand, many technological problems are present or coming up for which no solutions exist.

Better, reliable, simple, fast, sensitive and accurate monitors are needed to measure and study the behaviour of pollutants in water, air soil and food. Studies are needed of such environmental systems as the atmosphere and the energy balance of the earth. Studies on more careful use of earth resources are required. Research and development is necessary to face the problems of energy-supplies, acoustics, traffic and communications.

National research programmes will be started in international co-operation, in which physicists from all specializations can contribute in field measurements, data analysis, laboratory experiments and theory.

In my opinion, the European Physical Society could play an important role in the exploration of this new dimension of physics.

\section{Fourth Conference on Atomic Spectroscopy}

Amsterdam, The Netherlands, 11-14 July 1972

\section{Organized by the European Group for Atomic Spectroscopy (Specialized Division of EPS)}

With this 4th Conference, EGAS continued the series of annual conferences that started in Orsay in 1969.

The University of Amsterdam extended highly appreciated hospitality to the Conference in its Mathematics Lecture Building. The Group for Atomic Spectroscopy of the Zeeman Laboratorium actually carried out the organization.

In accordance with the aims of EGAS ("..., to facilitate contacts between members, ..., to stimulate the interest of young physicists in the field of atomic spectroscopy, ...") the conferenc fee was kept low (Dfl 35.-) and no restrictions were imposed, neither on the number, nor on the subject, of contributed papers that could be accepted.

Indeed, the Conference attracted a large number of young spectroscopists. Altogether 225 participants were registered, mainly from France, Fed. Rep. Germany, Netherlands, Sweden and U.K, but also from Bulgaria, Denmark, Israel, Italy, Poland, Spain, Switzerland, USA and Yugoslavia.

As in previous years, the programme was devoted to contributed papers, invited papers, round-table discussions and laboratory visits. The large number of submitted papers $(88$, each to be presented within 15 minutes) made it necessary to place two-thirds of them in parallel sessions.

Three invited papers each reviewed an interesting topic within the scope of EGAS :

1 UItraviolet stellar spectrophotometry by $C$. de Jager (Utrecht)

2 Analysis of atomic spectra ; the present situation and the future by $B$. Edlen (Lund)

3 Dye lasers and some of their applications by $B$. Bölger (Eindhoven).

Round-table discussions were organized on the following topics, suggested by individual participants and by the subjects of submitted papers :
1 Problems connected with spectra in the vacuum UV

2 Analysis of spectra

3 Lasers and their applications

4 Hanle effect and level crossing

5 Hyperfine structure and isotope shift ; measurement and interpretation

6 Theory and experiment of hyperfine structure and the evaluation of nuclear moments.

Summaries of discussions will be published in the EGAS abstracts lists.

The final paper was given by $P$. Jacquinot (Orsay) who discussed in detail the possibilities and limitations of high-resolution Fourier spectrometry and who announced the facilities of Laboratoire Aimé Cotton in this field - an idea that certainly is worth-while - to be considered and to be followed by other laboratories.

As many of the papers were of a preliminary character, no proceedings will be published.

E. Meinders 